\title{
Modelagem Matemática e Matemática Aplicada à Educação: uma Proposta de Iniciação Científica no Ensino Médio
}

\section{Luciana Santos da Silva Martino ${ }^{1}$}

Departamento de Matemática, Colégio Pedro II , Rio de Janeiro, RJ

Laboratório Nacional de Computação Científica, Petrópolis, RJ

Elson Magalhães Toledo ${ }^{2}$

Laboratório Nacional de Computação Científica, Petrópolis, RJ

Universidade Federal de Juiz de Fora, Juiz de Fora, MG

Regina Célia P. Leal-Toledo ${ }^{3}$

Universidade Federal Fluminense, Niterói, RJ

Resumo. As inovações tecnológicas e o avanço dos meios de comunicação via internet na direção dos jovens evidenciam a tardia porém inevitável renovação pela qual deverá passar o processo educacional brasileiro a fim de reaver o interesse de seus educandos. O conhecimento de Matemática propagado em nossas salas de aula, compartimentado e desconectado das demais áreas de conhecimentos, não estimula a criatividade e a curiosidade do educando e representa uma barreira para o desenvolvimento da cidadania do indivíduo.

Nesse artigo expõe-se a proposta de um currículo mais flexível, sob o ponto de vista da educação matemática, com oferecimento da disciplina de Modelagem Matemática e Matemática Aplicada, de caráter eletivo, a alunos do Ensino Médio do Colégio Pedro II. São apresentados alguns dos trabalhos desenvolvidos e expostos pelos alunos, durante a Semana Nacional de Ciência e Tecnologia de 2014.

Palavras-chave. Modelagem Matemática, Matemática Aplicada, Educação Matemática, Iniciação Científica, Interdisciplinaridade, Recursos Tecnológicos

\section{Introdução}

Em um ensaio, derivado da participação em um Simpósio da Academia Brasileira de Ciências, o documentarista João Moreira Salles discute a hipervalorização das artes e humanidades em detrimento das ciências "duras" e da engenharia, e as consequências desse processo no desenvolvimento tecnológico, científico e cultural do país. Salles argumenta citando o matemático César Camacho, que lembra que várias universidades brasileiras

\footnotetext{
${ }^{1}$ lusantos@lncc.br

${ }^{2}$ emtc@lncc.br

${ }^{3}$ leal@ic.uff.br
} 
têm vagas abertas para professores de matemática, não preenchidas pela falta de candidatos, e se questionando porque somente a arte teria "poderes civilizatórios", já que não estimulamos nossos jovens a visitarem um telescópio ou um laboratório de química ou de biologia, [10].

Sob diversos pontos de vista e por diversos motivos a experiência do ensino de matemática não reflete a grande mudança sofrida pela atividade matemática nos últimos 50 anos, [5]. E uma das consequências dessa falta de atualização está retratada nos resultados do PISA (Programme for International Student Assessment) que testa a capacidade individual de identificar e compreender o papel da matemática no mundo na construção de julgamentos bem fundamentados e de empregar a matemática de acordo com as necessidades individuais de um cidadão, [2]. Esse estudo embora apresente o Brasil com 391 pontos em matemática obtidos em 2012, em comparação com os 334 pontos obtidos em 2000, ainda nos coloca em posição inferior a de países como Alemanha com 514 pontos, Hong Kong com 561 pontos, Vietnã com 511 pontos e Portugal com 487 pontos, [8].

Nossos alunos não são capazes de reconhecer problemas onde a matemática pode auxiliar na construção de soluções, usam de maneira limitada o potencial oferecido pelos computadores e pela tecnologia da informação e desconhecem a atividade de pesquisa em matemática em crescimento no meio acadêmico.

Por exemplo, as preocupações ambientais que permeiam diversos trabalhos acadêmicos em Matemática Aplicada e Modelagem Matemática não são usualmente mencionadas em nosso ambiente matemático escolar. Em um contexto de crescente preocupação do homem em desenvolver técnicas que lhe permitam se relacionar de maneira mais equilibrada com o meio em que vive, nossa compreensão sobre os fenômenos que envolvem a natureza é muito limitada, [6]. E ainda mais limitada é a pauta desses temas em nossas aulas de Matemática no Ensino Médio.

"Sabemos que a gestão de nossas sociedades depende cada vez mais de um bom uso da ciência e da técnica. Nessas condições um pouco de lucidez não será demais: nem para os cientistas, em face das necessidades e exigências socialmente expressas, nem para os cidadãos, e para as possibilidades reais dos seus respectivos saberes." [9]

O rompimento com essa visão estagnada e estanque da matemática é o desafio que está posto em nossas salas de aula e somente através de sua superação alcançaremos real evolução em nosso sistema de educação em matemática e ciências.

\section{Um Novo Desenho da Sala de Aula}

É inegável a importância prática da matemática para a sociedade, [4], que a utiliza para avançar em seus conhecimentos que possibilitam tomar decisões adequadas à realidade e que auxiliam na construção de soluções para problemas de nossa era.

"O objetivo fundamental do "uso" de matemática é de fato extrair a parte essencial da situação problema e formalizá-la em um contexto abstrato onde o pensamento possa ser absorvido com uma extraordinária economia de linguagem. Desta forma a matemática pode ser vista como um instrumento intelectual capaz de sintetizar idéias concebidas em 
situações empíricas que estão quase sempre camufladas num emaranhado de variáveis de menor importância." [1].

Propõe-se o oferecimento da disciplina de Modelagem Matemática e Matemática Aplicada como componente de uma educação em tempo integral a alunos do Ensino Médio de escolas de Ensino Básico, Técnico e Tecnológico, com o desenvolvimento de atividades que busquem a interdisciplinaridade, a contextualização e a integração entre educação matemática e cidadania.

Estão entre as finalidades dessa proposta desenvolver a capacidade de usar a Matemática como instrumento de interpretação e intervenção do real, e contribuir para o estabelecimento de uma atitude positiva face à Ciência em geral, reconhecendo seu papel no progresso e desenvolvimento social e material, [3].

Assim temos o ciclo completo, sendo a Matemática Aplicada a direção que aponta da matemática para o mundo real e a Modelagem Matemática a que aponta do mundo real para a matemática, como mostra a Figura(1).

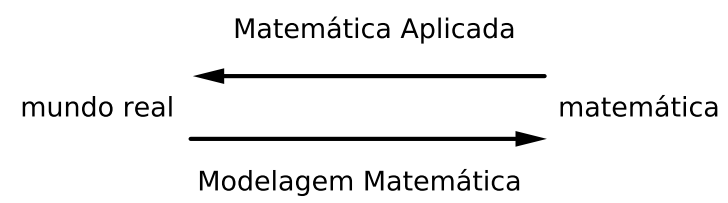

Figura 1: Matemática Aplicada e Modelagem Matemática.

Aliado a essa proposta está o uso de tecnologias digitais na promoção de novas possibilidades na abordagem dos conteúdos matemáticos. Oden e Belystschko, entre outros, destacam, no Report of the National Science Foundation Blue Ribbon Panel on SimulationBased Engineering Science, a simulação computacional como a extensão da ciência teórica nos casos onde esta se baseia em modelos matemáticos, [7].

Como primeiros resultados são apresentados trabalhos realizados por alunos do Ensino Médio do Colégio Pedro II, do Campus São Cristovão III. Esses trabalhos compõem um projeto de pesquisa em Modelagem Matemática e Matemática Aplicada à Educação do Departamento de Matemática da referida unidade escolar, e representam a viabilidade dessa proposta no sentido de uma educação matemática mais ampla e eficaz.

\section{A Produção Discente}

As atividades propostas, elaboradas de acordo com os conteúdos matemáticos vistos em sala de aula, individuais e/ou em grupo, foram realizadas em computadores disponibilizados pela unidade escolar, em seu Laboratório de Informática, com a utilização do software Geogebra. Também foram exibidos vídeos e filmes que contribuíram com a exposição do assunto do momento, sempre antes que se iniciassem as atividades com o computador.

Após uma série de encontros foram propostos aos alunos 19 temas, comuns às áreas de Matemática, Física, Química e Biologia, a serem escolhidos por grupos de no máximo 
três pessoas, para a elaboração de trabalhos e confecção de banners expostos, em parceria com o projeto financiado com o CNPq, Difusão e Popularização da Ciência: do Colégio Pedro II para o Mundo, na $11^{\mathrm{a}}$ Semana Nacional de Ciência e Tecnologia, com o tema "Ciência e Tecnologia para o Desenvolvimento Social". Todos os banners entregues foram devidamente avaliados, revistos e pontuados, de forma a comporem parte da nota do aluno na última etapa letiva de 2014. O objetivo era o de introduzir os alunos à iniciação e produção científica, entretanto observando que tratam-se de resultados referentes a esse primeiro contato com uma cadeira interdisciplinar, sendo assim portanto apenas o ponto de partida de todo um projeto de pesquisa a ser desenvolvido com os alunos dessa unidade escolar.

A tabela abaixo lista os temas propostos e a quantidade de trabalhos apresentados sobre cada um deles:

Tabela 1: Produção discente para a Semana Nacional de Ciência e Tecnologia - 2014.

\begin{tabular}{|l|c|}
\hline Tema & Trabalhos Apresentados \\
\hline Aviação e Círculos Máximos & 0 \\
\hline Funções Trigonométricas & 1 \\
\hline As Estações do Ano e a Duração de Horas de um Dia & 7 \\
\hline Números Complexos e a Forma Trigonométrica & 1 \\
\hline Distâncias no Sistema Solar & 8 \\
\hline Mapas e Projeções. Projeção Estereográfica & 1 \\
\hline Ondas e um Estudo das Marés & 5 \\
\hline O Número de Euler & 1 \\
\hline Eletricidade. Sinal de Corrente Alternada & 2 \\
\hline A Respiração & 3 \\
\hline Ondas Sonoras & 4 \\
\hline As Batidas do Coração & 8 \\
\hline Geometrias Não Euclidianas & 0 \\
\hline O Infinito e o Hotel de Hilbert & 5 \\
\hline O Método de Eudoxo e uma Aproximação para o $\pi$ & 1 \\
\hline A Série de Leibniz e uma Aproximação para o $\pi$ & 0 \\
\hline Fractais & 6 \\
\hline Matemática Aplicada a Finanças & 3 \\
\hline Crescimento Populacional & 8 \\
\hline
\end{tabular}

É apresentado nesse trabalho um exemplo da produção discente relacionada ao tema: A Respiração. 


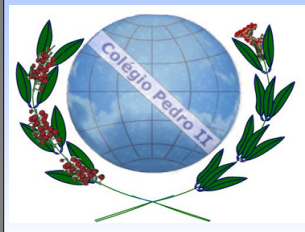

\section{A RESPIRAÇÃO \\ Autores: Louise Neves e Nathalia Corloski \\ Turma: 2106 - Profa: Luciana Martino \\ Colégio Pedro II - Campus São Cristóvão III}

\section{Introdução}

A respiração é um processo vital para os seres humanos. Através dela ocorrem as trocas gasosas entre o meio externo e o indivíduo (entra oxigênio e sai gás carbônico), de suma importância para o bom funcionamento do organismo. A inspiração é a entrada do ar pelas vias respiratórias até chegar ao pulmẫ; Durante o processo há uma contração do diafragma e dos músculos intercostais externos; fazendo com que o volume pulmonar e o tamanho da caixa torácica aumentem. A expiraçăo e a saída do ar presente nos pulmõ més vis respiratón para o ambiente externo; nela, o diafragm

consequentemente, provocam a diminuição do tamanho da caixa torácica e do volume pulmonar.

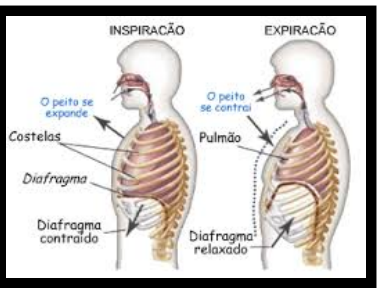

A complexidade dos pulmões aumenta conforme a independência de água no ciclo de vida do animal aumenta. Nos mamiferos, os pulmões são grandes e ramificados internamente, formando pequenas bolsas: os alvéolos. Ocorre dia e noite, sem parar. Nós podemos sobreviver determinado tempo sem alimentação, mas não conseguimos ficar sem respirar por mais de algun poucos minutos. Além disso, o nosso organismo obtém energia química nos alimentos pelo processo da respiração celular, realizada nas mitocôndrias, com a participação do gás oxigênio obtido no ambiente. A glicose é um os principais "combustiveis" utilizados pelas células vivas na respiração.

Glicose + oxigênio gás carbônico + água + energia É esse tipo de fenômeno que ocorre sem parar no interior das células viva, liberando a energia que garante a atividade dos nossos órgãos por meio do trabalho das células.

0 ar entra em nosso corpo por duas cavidades existentes no nariz: as cavidades nasais direita e esquerda. Elas são separadas completamente por uma estrutura chamada septo nasal; comunicam-se com o exterior pelas aberturas denominadas narinas e com a faringe pelos cóanos. As cavidades nasais são revestidas internamente pela mucosa nasal. Essa mucosa contém um conjunto de pêlos junto as narinas e fabrica uma secreção viscosa chamada muco. Os pêlos e o muco atuam como filtros capazes de reter microorganismos e partículas sólidas diversas que penetram no nariz como ar. Por isso, devemos inspirar pelo nariz e não pela boca: 0 ar inspirado pelo nariz chega aos pulmões mais limpo do que o ar inspirado pela boca. Além de filtrado, o ar é também adequadamente aquecido e umidificado no nariz.

\section{Objetivo:}

O objetivo do nosso trabalho é aplicar ao estudo do fenômeno químico da respiracão através da análise da variação do volume de ar nos pulmões em função da pressão no interior dos mesmos e em função do tempo.

\section{Metodologia:}

O volume na caixa torácica e a pressão no interior dos pulmões são grandezas inversamente proporcionais de fato. $\mathrm{Na}$ inspiração, quando o grandezas nuersaxa diminui. Na expiração é contrário, os músculos relexam reduzindo o volume torácico e aumentando a pressão nos pulmões.

\section{Modelo Físico:}

Modelo para explicar a respiração, feito com garrafa de plástico cortada ao meio, bexiga, rolha e canudo; a película de borracha presa no fundo representa o diafragma.

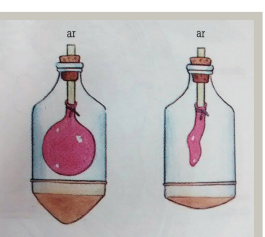

\section{Modelo matemático:}

Nossa respiração é periódica e involuntária. O ritmo (período) da respiração é controlado pelo bulbo, localizado na parte inferior do cérebro. $O$ controle desse ritmo pelo bulbo deve-se principalmente à percepção da concentração de gás carbônico no sangue. A cada respiração normal de um adulto do sexo masculino,
aproximadamente $0,5 \mathrm{~L}$ de ar é inspirado, e esta mesma quantidade é expirada. aproximadamente $0,5 \mathrm{~L}$ de ar è inspirado, e esta mesma quantidade é expirada. No entanto, em uma inspiração ou expiração muito profunda, essa quantidade pode aumentar. Suponha que o volume de ar nos pulmões de um individuo adulto saudável, do sexo masculino, em repouso, a partir de um instante inicial $t=0$, possa ser representado aproximadamente pela função

$$
V(t)=2,65-0,25 \cdot \operatorname{sen}(2 \pi t / 5+\pi / 2)
$$

sendo to tempo em segundos e $V(t)$ o volume de ar nos pulmões, em litros, após t segundos do instante inicial. De acordo com esse modelo temos o seguinte

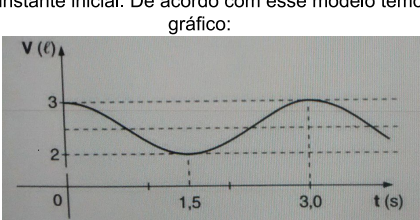

existe um volume de ar que permanece nos pulmões. No caso do

Após a expiração, existe um volume de ar que permanece nos pulm
indivíduo em questão, qual é esse volume? $2,4 \mathrm{~L}$ Os pulmões não enchem completamente durante a inspiração n comptameste durante a expiracão. Em geral na respiracão normem esvaziam de um terço do ar dos pulmões é expirado e substituido pela mesma quantidade de ar inspirado. Este ar renovado (volume de ar corrente) mistura-se com o ar remanescente (volume residual) já existente nos pulmões.

\section{Conclusão:}

Concluímos que a matemática pode ser aplicada em várias ciências como na biologia. Sendo a respiração como um todo um processo vital para o desenvolvimento da vida na Terra.

\section{Bibliografia:}

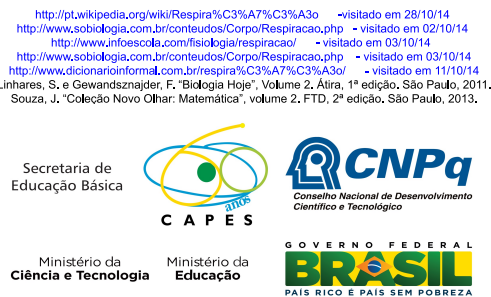

Figura 2: Produção discente sobre o tema A Respiração. 


\section{Conclusões}

Esses trabalhos evidenciam nossa proposta de disponibilizar para alunos do Ensino Médio regular e integrado temas de pesquisa e atuação em Matemática, capazes de despertar o interesse dos alunos a respeito dos conteúdos matemáticos vistos em sala de aula, seja através da Modelagem Matemática, com ramificações para outras ciências, como física, química e biologia, ou da Matemática Aplicada, através do aprofundamento e aplicação desses conteúdos.

Entretanto observamos em alguns trabalhos a falta dos conceitos da metodologia científica por parte dos alunos, o que implica em uma exposição não muito clara do tema e por vezes pouco rigorosa. Levamos em consideração o fato de ter sido este o primeiro contato desses alunos com uma proposta interdisciplinar, o que configura uma dificuldade adicional, já que os posiciona de forma ativa na construção de seu conhecimento, rompendo portanto com a zona de conforto que frequentaram durante todo seu histórico escolar.

Com o objetivo de aprimorar esse pensamento científico daremos continuidade a esse projeto através do aprofundamento dos conceitos da Modelagem Matemática e da Matemática Aplicada durante o ano letivo de 2015, de forma que os temas possam ser estudados com maior profundidade e rigor.

\section{Referências}

[1] R. C. Bassanezi, Ensino-Aprendizagem com Modelagem Matemática, uma Nova Estratégia, Editora Contexto, (2009).

[2] W. Blum, ICMI Study 14: Applications and Modelling in Mathematics Education Discussion Document, Future of Mathematics Education in Europe Conference, vol. 51, 149-171, (2002).

[3] M. G. E. C. Fonseca, C. M. C. da Fonseca, I. M. F. do C. Lopes, M. T. P. Cardoso, A. de A. Martins, M. I. P. do Vale, L. M. D. da Fonseca e J. M. M. C. e Silva, Programa Componente de Formação Científica - Disciplina Matemática Aplicada, Agência Nacional para a Qualificação do Ensino Profissional, Ministério da Educação de Portugal, (2005).

[4] J. de Lange, Using and Applying Mathematics in Education, International Handbook of Mathematics Education, Cap 2, 49-97, (1996).

[5] L. Lovász, Trends in Mathematics: How they could Change Education, Educational Studies in Mathematics, vol 86, (2006).

[6] L. S. da S. Martino, Solução Numérica de Escoamentos em Águas Rasas pelo Método de Diferenças Finitas, Tese de Doutorado em Modelagem Computacional, Laboratório Nacional de Computação Científica, (2013). 
[7] J. T. Oden, T. Belytschko. J. Fish, T. J. R. Hughes, C. Johnson, D. Keyes, A. Laub, L. Petzold, D. Srolivitz and S. Yip, The NSF Blue Ribbon Panel on Simulation-Based Engineering Science, Technical Report, National Science Foundation, (2006).

[8] PISA - Programme for International Student Assessment, Instituto Nacional de Estudos e Pesquisas Educacionais Anísio Teixeira, (2015).

[9] I. Prigogine, A Nova Aliança, Universidade de Brasília, (1991).

[10] J. M. Salles, Um Documentarista se Dirige a Cientistas - Arte, Ciência e Desenvolvimento, Folha de São Paulo, (2009). 